


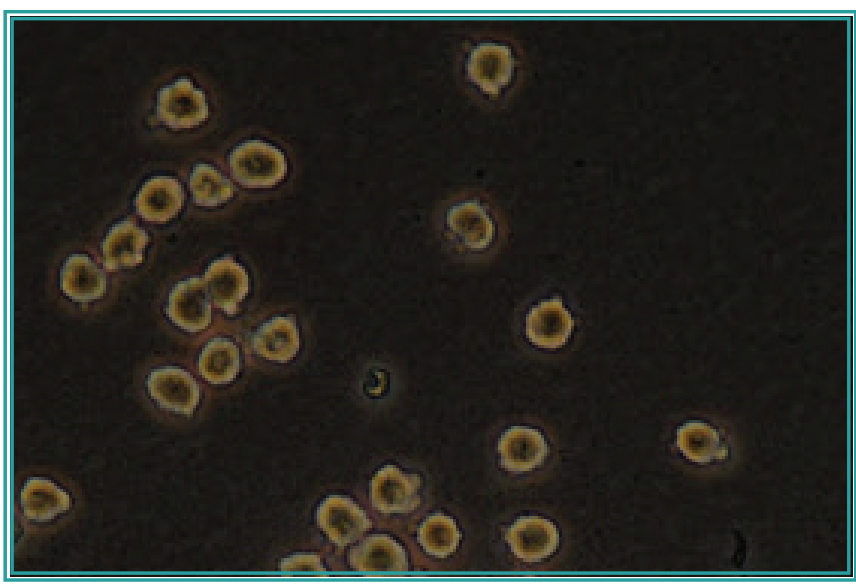

Figure 1. Hybridoma cells grown in tissue culture. Credit: Gerry Shaw, the EnCor Biotechnology Lab, CC-BY-SA.

monoclonal and polyclonal. Each has its own benefits and drawbacks, making it useful for different kinds of research. Hybridoma mAbs are precise and reproducible, yet come with high requirements in terms of costs, expertise and time. Additionally, they can lose specificity over time, since some hybridomas are prone to genetic drift. Recombinant mAbs (rAbs), produced using nucleic acid sequences in a similar manner to monoclonal proteins, provide researchers better control, but the need for expertise during development is high. Polyclonal antibodies (pAbs) have multiepitope binding properties; however, there is a finite supply and an inability to rigorously define the clonal composition in a polyclonal mix means performance can vary batch-to-batch. Their ability to bind multiple epitopes also has the potential to be a burden - while advantageous for some applications, this could be a source of troublesome background and cross-reactivity [3]

However, reproducibility concerns are widespread for all antibodies. In just one of the multiple studies on antibody reliability, the Human Protein Atlas examined over 5000 commercial antibodies and demonstrated that over $50 \%$ could not be used in the proposed application [2]. This has huge implications for research conducted using these antibodies.

"We now have access to multiple antibody characterization and validation tools such as mass spectrometry and the ability to knockdown or knockout genes to alter protein expression in cells and animals, which allows us to better assess reagent specificity and to be more precise with protein detection than ever before," noted Alejandra Solache (Abcam, Cambridge, UK). "However, as these techniques have become more widespread and accessible, we as well as other researchers are finding that some of the reagents that we have relied on for decades might not be as specific as originally thought. This has resulted in an important shift in the way that we develop, test and use antibodies."

A prime example of the cost of mistakes in antibody validation can be found in a 2017 study, which suggested that two decades of research attempting to target an estrogen receptor for breast cancer treatment had been wasted owing to insufficiently validated antibodies that were not appropriate for the target in the original paper [7]. Overall, however, the problems facing antibody research have a variety of potential sources.

"Hybridomas are not stable and often not entirely clonal [11] so if you buy something that's made in a hybridoma today and if you buy something that is made in a hybridoma in a year, the end product that you receive can differ a lot. This can differ in the purity, it can differ in the fine composition, and it can also just be a completely different molecule," commented Michael Fiebig (Absolute Antibody, Oxford, UK). "At the same time, it's also where you get your antibodies from. The antibody market is very diverse and there are a lot of companies that just focus on re-selling antibodies and they might in turn re-sell to other companies. Knowing where your antibody is from and knowing whom to talk to if you are running into any issues is a big challenge, and science is not simple."

Longevity and traceability are just some of the potential challenges. Additional complications include not checking properties such as affinity constants and selectivity, the availability of information on reference standards and the original development and production process, and long-term availability [2]. Of course, with researchers continually striving to answer new questions, they will need to use antibodies in new ways that they might not have been validated for. As a result, responsibility falls on both researchers, to ensure their antibodies are useful for their new application, and on manufacturers, to provide robust antibodies that do what they say they will do, and perhaps go a little beyond.

\section{SOLVING THE CRISIS}

While the problem is certainly appreciated, the next steps are uncertain. For example, some have suggested the complete phasing out of pAbs is required, yet others disagree [3]. It has also been suggested that recombinant versions of all mAbs should be produced. "We can use recombinant methods to overcome almost every aspect of the $m A b$ production path," explained Fiebig. He believes we will see a drift toward widespread production or rAbs. "This will be pushed by the end-users who are understanding the advantages with regards to reproducibility, but also the advantages in terms of being able to explore new biology the recombinant production brings. We are going to see a lot of resistance to this from the side of the industry, but in the end, the end-users - the people really doing the science - they are really going to push this through."

Carl Ascoli (Rockland Immunochemicals Inc., PA, USA) and Birte Aggeler (Bio-Techne, MN, USA) agree that end-users are key: "The perspective of researchers will likely evolve, resulting in 
a better understanding of when, and when not, to use an antibody in a 'fit-for-purpose' manner" [3]. They also feel that universal standards for application-specific antibody validation are needed.

Meanwhile, manufacturers are making moves to improve things from their side. "Our most popular products are new versions of traditional, well-established antibodies," noted Fiebig. "A lot of hybridomas are not stable, in fact it's inherent to hybridomas not to be stable as they are B-cell fusions with cancer cells. You can get subtype switching and all of a sudden your blocking antibody starts depleting cells. With the recombinant approach that we're taking, you get a precisely defined product, and you can overcome impurities that might be inherent to the hybridoma, like additional light chains or additional heavy chains. So, it's doing something new but it's doing something that is going to be reliable and reproducible over time."

Using recombinant cloned antibodies is one way to ensure reproducibility, and knock-out cell lines are a good way to confirm specificity. All-in-all, selecting the right antibody comes down to both researchers and suppliers. "Suppliers need to make use of the most appropriate available techniques when producing and validating antibodies, so that researchers can be confident about quality," explained Solache. "And researchers also need to stay as up-to-date as possible on the best type of antibodies to use, and where possible choose an antibody that has been shown to work in the specific applications and/or species relevant to their own experiments." Several open platforms are now available on the internet providing researchers the opportunity to both produce and access reviews of antibodies, such as antibodypedia and pAbmAbs. Checklists have also been produced to help users ensure validation of their antibody [8].

\section{LOOKING TO THE FUTURE OF ANTIBODY RESEARCH}

There is a clear need to improve practices in antibody research, and that need appears to be fairly well-known by the research community. With technology constantly improving, there will be ever new ways to harness antibodies to answer novel research questions, while ensuring the antibodies are validated for that use and the resultant research is reproducible. Solache is excited about the future of the field: "With the increased focus on reproducible, high-quality antibodies, we expect to see a continuing shift towards recombinant monoclonals, which in turn will help with reproducibility, and with this we will see even more of the blurring of the distinction between research, diagnostic and therapeutic antibodies that we are already seeing."

Written by Francesca Lake doi: 10.2144/btn-2019-0045

\section{MONEY DOWN THE DRAIN}

The use of poorly characterized and ill-defined antibodies wastes materials,

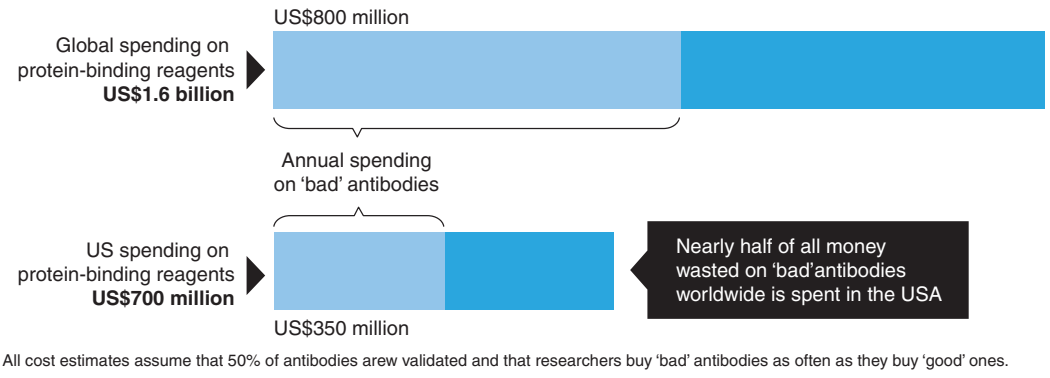

Figure 2. An infographic showing the wastage caused by bad antibodies.

Reproduced with permission from [10].

(A) Specific for target of interest

Figure 3. Western blots demonstrating antibody validation using wild-type and knockout cell (1), confirming its specificity. By comparison when a nonspecific antibody (here rabbit lysate, resulting in a band in the $\mathrm{KO}$ lane (2), demonstrating a lack of specificity. The nonspecific antibody was subsequently removed from the catalogue. Credit: Abcam's Antibody Validation Lab, Cambridge, UK.

KO: Knockout; WT: Wild-type.

\section{REFERENCES}

1. Köhler $\mathrm{G}$, Milstein $\mathrm{C}$. Continuous cultures of fused cells secreting antibody of predefined specificity. Nature 256(5517), 495-497 (1975)

2. Weller MG. Quality issues of research antibodies. Anal. Chem. Insights 11, 21-27 (2016).

3. Ascoli CA, Aggeler B. Overlooked benefits of using polyclonal antibodies. BioTechniques 65(3), 127-136 (2018).

4. Mendoza P, Gruell $H$, Nogueira L et al. Combination therapy with anti-HIV-1 antibodies maintains viral suppression. Nature 561, 479-484 (2018).

5. Kunamneni A, Ye C, Bradfute SB, Durvasula R. Ribosome display for the rapid generation of high-affinity Zika-neutralizing single-chain antibodies. PIOS ONE 13(11), e0205743 (2018).

6. The Wistar Institute. Synthetic DNA-delivered Antibodies Protect Against Ebola in Preclinical Studies Representing a Novel Platform for Antibody Therapies for Outbreak Infections. https://wistar.org/news/press-rel
ies-protect-against-ebola-preclinical-studies

7. Andersson $\mathrm{S}$, Sundberg $\mathrm{M}$, Pristovsek $\mathrm{N}$ et al. Insufficient antibody validation challenges oestrogen receptor beta research. Nat. Comm. 8, 15840 (2017).

8. Weller MG. Ten basic rules of antibody validation. Anal. Chem. Insights 13 , 1177390118757462 (2018).

9. Soto C, Bombardi RG, Branchizio A et al. High frequency of shared clonotypes in human B cell receptor repertoires. Nature 566, 398-402 (2019).

10. Bradbury A, Plückthun A. Reproducibilty: standardize antibodies used in research. Nature 518(7537), 27-29 (2015).

11. Bradbury ARM, Trinklein ND, Thie $\mathrm{H}$ et al. When monoclonal antibodies are not monospecific: hybridomas frequently express additional functional variable reasons. MAbs 10(4), 539-546 (2018). 